This is a self-archived version of an original article. This version may differ from the original in pagination and typographic details.

Author(s): Siitonen, Marko; Aira, Annaleena

Title: Technology-Mediated Communication in the Workplace

Year: 2020

Version: Accepted version (Final draft)

Copyright: (c) 2020 Taylor \& Francis

Rights: In Copyright

Rights url: http://rightsstatements.org/page/lnC/1.0/?language=en

Please cite the original version:

Siitonen, M., \& Aira, A. (2020). Technology-Mediated Communication in the Workplace. In L. Mikkola, \& M. Valo (Eds.), Workplace Communication (pp. 96-109). Routledge.

https://doi.org/10.4324/9780429196881-8 
Print-proof version of: Siitonen, M., \& Aira, A. (2020). Technology-mediated communication in the workplace. In L. Mikkola \& M. Valo (Eds.), Workplace communication. London: Routledge. Pp. 96-109

\title{
Technology-mediated Communication in the Workplace
}

\author{
Marko Siitonen and Annaleena Aira
}

\begin{abstract}
Technology-mediated communication has become an integral part of work and the workplace. Since the early days of digital communication technology, views of both the affordances and uses of communication technology have become more varied and complex. Understanding the reality of communication technology at work means taking into account its ubiquitous and ever-changing nature as well as the interpersonal relationships and social networks in which it is used. This chapter explores the ways in which communication technology relates to building mutual understanding and trust as well as managing networks and coworker relationships. Knowledge of these key issues is used to present ideas about how members of the workplace can design and facilitate the use of communication technology at work.
\end{abstract}

\section{Introduction}

Contemporary workplaces are completely dependent on communication technology in their day-to-day operations. For example, the geographical distribution of the workforce, mobile work, interorganizational collaboration, and global market operations all rely on available technological solutions. Similarly, many current organizational structures, professions, and types of work could not exist without the technological affordances available, that is, the multiple possibilities of communicating offered by the technological environment (Gibson 2015 [1986]). Technology-aided collaboration has changed work-related processes, too. For example, communication technology offers workers novel ways of participating in joint efforts. Technological tools, such as project management software and version control software, affect the visibility of tasks and contributions, which in turn can be used as a way 
for participants to communicate their viewpoints, level of activity, and commitment to the joint effort.

In the workplace, navigating the landscape of technology-mediated communication entails a continuous need to learn and adapt. Old solutions, such as telephones and email, are now combined with new tools and their applications, forming a complex reality that requires human understanding. The aim of this chapter is to explore the field of technology-mediated communication at work with an emphasis on social interaction and interpersonal relationships, which are at the heart of all forms of collaboration. Knowledge of the dynamics of technology-mediated social interaction, and how it has developed into its current state, makes it possible to see beyond individual technical solutions and appreciate the emergent ways in which people intertwine communication technology with their work. Such an understanding is especially useful in expert and knowledge work that makes extensive use of communication technology. Ultimately, it enables planning for change and decision-making that best supports the organization and its employees' needs.

\section{Technology-Mediated Communication at Work: From Simple to Complex Views}

To understand the role communication technology plays in the contemporary workplace, it is useful to look back at the trajectory of how it became an essential feature of work in the first place and how people's orientation toward such technology changed as it became more commonplace.

Overall, the discussion surrounding technology-mediated communication has undergone a movement from simple to complex viewpoints. Similarly, the focus of this discussion, which was previously the effect of single tools or channels of communication, is now the interplay of human actors in a technology-rich communication landscape. Viewpoints prevalent in the 1970s, the 1980s, and the early 1990s often emphasized the effect of what was then labeled new technology: email, bulletin boards, group support systems, and the like. A distinction between "rich" and "lean" technology was based on comparisons between the qualities of such technology and face-to-face communication, and many expressed concerns about the missing dynamics of nonverbal communication (Culnan \& Markus 1987). Discussions of social presence (Short, Williams, \& Christie 1976) and media richness (Daft \& Lengel 1984; 1986) typified this line of thinking. Put simply, technology-mediated communication was seen as inferior to the gold standard of face-to-face communication and therefore less suitable for complex relational communication. At the same time, however, the adoption rates of information and communication technology 
demonstrated that there was a clear demand for novel ways of supporting collaboration in working life.

The simplistic views related to the first wave of digital communication technology were challenged, but not entirely replaced, by a stream of new viewpoints in the 1990s and early 2000s. By this time, internet use had become widespread, and it was possible to learn from everyday uses of communication technology instead of relying on artificial test sessions or speculating on long-term effects. Ideas such as the social information processing model (Walther 1992) proposed that given sufficient time, people can learn about and adapt to the limitations of a channel of communication. At times, people used communication technology in ways that transcended the processes and dynamics of face-to-face communication. For example, forming impressions of others and building a sense of relational intimacy could sometimes be faster and stronger than in face-to-face contexts - "hyperpersonal" instead of interpersonal (Walther 1996). Moreover, people even embraced the lack of nonverbal social cues and saw focusing on verbal cues as an affordance that enabled them to concentrate on decision-making or idea creation instead of relational concerns (Jonassen \& Kwon 2001).

Finally, and most importantly, it was maintained that to understand technologymediated communication, one had to understand the lived reality of the people using it. Instead of emphasizing a distinction between face-to-face and online interpersonal relationships, for example, a more fruitful approach was to see the physical and technologyrelated dimensions of social interaction as interconnected parts of everyday communication (Wellman \& Haythornthwaite 2002). Put another way, if one wants to understand technology-mediated communication in the workplace, one should observe people's offline and nontechnological communication as well. Just because a technological tool or application works in one setting or for some people, it will not automatically be embraced by others in dissimilar situations. For example, there may be a team that excels in knowledge sharing and time management, and it may seem that their success is linked to the technological tools they use. However, a closer inspection may reveal that their success has a great deal to do with the way they organize their meetings and discuss their work with each other. Therefore, marketing the same technological tools as a solution for another team may not produce the same results if the communicative aspects of their work are not taken into account and facilitated at the same time.

In contemporary workplaces, technology-mediated communication is embedded in a complex communication landscape that poses increasing demands for workers (Hämäläinen, Lanz, \& Koskinen 2018). Becoming aware of, and learning to adapt to, available affordances 
are essential to enabling people to build and maintain interpersonal relationships and networks despite the barriers of place, time, or organizational boundaries. In knowledge work, teaming platforms, phone calls, face-to-face meetings, social media, and email correspondence, to give just a few examples, come together in an amalgam of affordances - a landscape of possibilities for addressing work-related needs.

\section{The Ubiquitous and Ever-Changing Communication Technology}

In the 2010s, technology-mediated communication in working life has exhibited two partly parallel trends. The first of these is the realization that communication technology is ubiquitous. The second trend is continuous change and unpredictability, and it stems from the fact that technological solutions and tools continue to contribute to the communication landscape in new and surprising ways.

The ubiquity of communication technology means that in order to understand the reality of work in the 2020s, one also has to understand the nature and affordances of communication technology used in the context of work. Whether one is looking at human resource practices, leadership, the creation of an organizational culture, or knowledge management, technological tools have become a pervasive element of the pattern of work. For example, understanding the paradoxical relationships between employee engagement and burnout was a relevant issue in working life even before the advent of digital communication technology. However, if one wants to understand or manage employee engagement and burnout in today's workplace, one has to take into account the use of communication technology on many levels (Ter Hoeven, van Zoonen, \& Fonner 2014).

The ubiquitous influence and importance of communication technology are evident in the way traditional concepts have been retrofitted with prefixes such as "virtual" or "e-" to denote the difference in contemporary ways of working. These include concepts such as eleadership (for a review, see, e.g., Dasgupta 2011) and virtual teams (for a review, see, e.g., Gilson, Maynard, Young, Vartiainen, \& Hakonen 2015). The affordances of new technology have brought about a major shift with respect to traditionally important issues, such as how leaders and followers relate to one another (Avolio \& Kahai 2003). For example, social media links between employees and their supervisors have the potential to challenge traditional hierarchies while at the same time creating new ones between those who use the services and those who do not.

The second trend deals with the ever-changing technological landscape and the unpredictability it introduces. For example, the proliferation of social media has opened up 
new ways of understanding phenomena, such as impression management, identity, privacy, and the dynamics of social networks in general (Boyd \& Ellison 2008). All of these are evident in human communication in general, and they are therefore relevant for workplace communication as well. Hobbies and other activities that once were completely private have become publicly visible via social media, causing challenges for professional impression management. The so-called long tail of online identity - the way our past activities are visible for years afterwards, and impact how we are seen today - has become relevant for us in unforeseen ways, not only as citizens but perhaps especially as professionals. In the era of shared calendars, instant messaging software, enterprise social networking, and workplace surveillance technology, workers' needs of privacy management and the way privacy management is performed differ from the earlier state of affairs, in which such technology was not available (Chang, Liu, \& Lin 2015; Chory, Vela, \& Avtgis 2016).

What makes the topic of the ever-changing technological landscape challenging is the sheer speed and breadth of technological development. Basic questions related to communication have to be revisited repeatedly by those interested in developing workplace communication. There is little possibility of offering simple lists of dos and don'ts that would guide users across contexts. This includes both emerging technology and the novel ways in which people learn to use the affordances of existing tools and channels of communication. This kind of challenge has been addressed by the line of studies on technology overload at work. This issue can be understood only in the historical context of ubiquitous information technology and the demands it places on individual workers and organizations (KarrWisniewski \& Lu 2010), and it certainly could not have been fully anticipated by the early developers of communication technology.

Similarly, the issue of resisting technological adoption at work has emerged as organizations implement new communication technology into their daily operations. Applying communication technology to day-to-day work has illustrated that several pressures, stemming from both within and outside the organization, impact the way employees choose to adopt or resist technology (Choudrie \& Zamani 2016). It may be, for example, that users develop workarounds, such as using an existing social media platform to conduct work-related meetings instead of the specially ordered corporate version. In some cases, these workarounds may end up being more efficient than using the officially sanctioned platforms, because an existing communication technology is sometimes already used to fulfill a function similar to the one proposed for a new tool. It is therefore important to discuss the existing uses of communication technology in the workplace and to evaluate 
the practices that have been adopted in interpersonal and team communication before attempting to introduce new tools and solutions.

\section{Working Together Online}

Successful collaboration at work requires more than choosing the right tool for the task. In addition to the technological dimension, understanding the core dynamics of interpersonal and team communication is required. Successful online collaboration at work requires knowledge of a variety of communication-related phenomena. These include reaching a mutual understanding of the content and process of collaboration (Cheng, Yin, Azadegan, \& Kolfschoten 2016), building trust between collaborators (Choi \& Cho 2019), managing complex networks with a large number of interpersonal relationships (Planko, Chappin, Cramer, \& Hekkert 2017), and maintaining different kinds of interpersonal relationships (Ou \& Davison 2016).

\section{Reaching a Shared Understanding of Work Goals and Tasks}

To be able to collaborate successfully, collaboration partners need to create a shared understanding of what they are doing together (de Vries, van Bommel, \& Peters 2018). In online collaboration, a shared understanding is needed to determine what kind of work and communication processes are part of a project, what should be prioritized, what kind of work distribution is needed, and through what kind of communication processes should the project be managed. A shared understanding increases task orientation in technology-mediated communication. Conversely, the lack of a shared understanding results in a focus on expressing differing opinions and resolving misunderstandings instead of an emphasis on the goals and tasks of collaboration (Hart \& McLeod 2003). This means that when the focus of technology-mediated communication is resolving misunderstandings and expressing opinions, it is advisable to address such misunderstandings as soon as possible and prioritize communication that aims at building a shared understanding.

Shared understanding - or shared mental models of the work tasks - is connected to knowledge management (Hsu, Chang, Klein, \& Jiang 2009). Sharing knowledge in technology-mediated teams, for example, increases the sense of belonging and cohesion and improves the building of interpersonal relationships with other team members (Baehr \& Alex-Brown 2010). Adequate knowledge sharing between members of the workplace is essential to achieving success and reaching goals at work. Knowledge sharing is one of the crucial factors in creating and maintaining fruitful interpersonal relationships (Sias 2009); 
thus, interpersonal relationships play an important role in building a shared understanding in online collaboration as well.

In practice, it is not always easy to know what kind of knowledge needs to be shared. For example, members of a new work team need to draw conclusions about what the other members already know and therefore what they still need to learn. Every team member should consider what kind of knowledge they need and should share. Knowledge sharing can be facilitated by certain team members or by the team leader. Working in technologymediated settings may increase the complexity of these types of negotiations by increasing the gap in individual perceptions of what is shared in the first place (Leinonen \& Bluemink 2008). The more channels and tools are available, the more likely it will be that information gets lost or does not reach all team members. On the other hand, many technological solutions make the sharing of knowledge easier and more visible. It is therefore important in such cases to devote sufficient time and effort to sharing information instead of assuming that team members are similar in terms of what they know and their ways of working.

\section{Building Trust in Online Collaboration}

The building and maintenance of trust are crucial for collaboration, because without trust, collaboration is fragile and partners may avoid communication and work alone (Ou \& Davison 2016). Avoiding communication can be easier in technology-mediated environments than in face-to-face encounters. Trust involves accepting the vulnerability that accompanies dependency (the other's acts have an effect on me) and relying on the other not to take advantage of that vulnerability (Lewicki \& Bunker 1996). Trust greatly affects the information sharing that is vital for collaboration (Cheng et al. 2016). In collaboration between organizations, trust can be understood as an organization's decision to rely on another organization (Zhong, Su, Peng, \& Yang 2017). At the interpersonal level, trust is built and maintained in interpersonal relationships between collaborators.

Trust develops in the process of maintaining interpersonal relationships (Lewicki \& Bunker 1996). Often, trust building is not a conscious process. People learn how to build and maintain trust as they learn how to communicate and collaborate with other people. In a given relationship, it may be difficult to identify the kinds of acts that have resulted in the development of trust. Trust always includes a risk that the other's acts will not be trustworthy; otherwise, trust would not be needed (ibid., 116). Trust is particularly relevant when collaboration includes a high degree of uncertainty and conflicts of interest (de Vries et al. 2018). 
Trust is an important part of technology-mediated collaboration. Typically, people tend to favor face-to-face situations when building trust, at least when they are asked about it (de Vries et al. 2018; Ou \& Davison 2016; Planko et al. 2017). However, trust can also be built and maintained via technology-mediated communication through regular and meaningful interaction (de Vries et al. 2018). Technology-mediated communication does not always make trust building more difficult than it is in face-to-face situations. In online collaboration, the goals of collaboration are often in the interests of all parties, which facilitates the building of trust (ibid.).

It is typical of technology-mediated communication that in the early stages of online collaboration, trust may arise even more quickly than expected. This phenomenon is called swift trust (Meyerson, Weick, \& Kramer 1996). Swift trust occurs quickly, because it is directed toward a wider entity - a group of which the new individual collaborator is a part. When collaborators who usually work in different organizations and who are unacquainted with one another come together in a new team, swift trust may be based on previous experiences of cooperation between the organizations themselves. When collaborators work in the same workplace, swift trust is created on the basis of the professional group the partner represents. Swift trust is useful for collaboration, because people always need a sufficient level of trust to be able to work together. Later, collaborators gain experience-based knowledge of each other, which leads to the replacement of swift trust with interpersonal trust or, in unfortunate cases, its erosion.

In online collaboration, the building of trust can be consciously fostered in several ways. Transparency helps in building trust (de Vries et al. 2018). Trust can be fostered by using tools that allow the recording or archiving of communication. This has been referred to as the affordance of persistence (Evans, Pearce, Vitak, \& Treem 2017). For example, technology may allow an individual to review a new collaboration partner's past work or to evaluate their communication behavior in enterprise social networking. This helps people evaluate the trustworthiness of others before any interpersonal contact takes place, and in online collaboration, the reputations of others and positive evaluations of their ability and integrity foster trust (Choi \& Cho 2019; de Vries et al. 2018). Moreover, the ability to instantly connect with others and to ask for or share information supports the development of mutual understanding (Ou \& Davison 2016). A clear structure and appropriate practices for online collaboration, as well as a strong emphasis on shared goals and project-related content, may also help collaborators build trust (Choi \& Cho 2019; de Vries et al. 2018). 


\section{Managing Networks}

In working life, interpersonal relationships form multilevel social networks, often across organizational boundaries. Such networks cannot exist without the help of communication technology, and the forms of communication technology should be chosen on the basis of the breadth and scope of the networks. The characteristics of communication technology can facilitate or enable the permeability of the boundaries of groups, teams, and organizations (Borgatti \& Halgin 2011; Monge \& Contractor 2003).

Focusing on interorganizational networks provides an opportunity to understand many of the key characteristics of technology-mediated communication. Networking has become a common way of organizing work and of solving global, complex problems (de Vries et al. 2018). Multi-professional networks cross organizational boundaries, and they can be formal and structured as well as informal and flexible. Technology-mediated interaction reinforces the possibilities of collaboration, actors' mutual relationships, wider involvement, and the self-organization of communities (Lin 2018).

Well-functioning practices in technology-mediated communication are developed over time, and they have an enormous effect on the functionality of a network. How practices came to be and how they could be changed or challenged are often analyzed from a structuration perspective (Giddens 1984; Poole \& McPhee 2005). Simply put, our social reality is constructed on the basis of the connections between individuals' actions and social structures, each affecting the other in a continuous process. The process of structuration happens automatically, that is, it cannot be stopped or prevented. Once social structures are in place, they easily become normalized, and we have to become aware of their existence before we can change them. For example, such structures include routines in meetings and in collaborative planning, shared rituals, combined tasks, and continuing open discussion (Scott 2013).

A communication perspective on networked collaboration stresses the importance of discourse (communication), dialogue, and coorientation (Koschmann 2016). It is through active communication that the entire process of the network is constituted. Various actors representing different orientations and interests take part in the network and engage in discussions concerning the issues that need to be addressed at any given time. Ideally, this constitutive communication is dialogical in nature, which means that the interaction between network members is reciprocal and symmetric. Lastly, as stated by Koschmann (ibid.), coorientation means the process in which participants relate their actions to conform to joint goals. A communicative, dialogical, and cooriented process of establishing a well-functioning 
technology-mediated network calls for devoted leadership, attentive membership, and informed decisions regarding the objectives of the joint work.

Networked collaboration is not automatically successful. Overemphasizing the structural elements of the network, contrasting individual identities instead of developing a shared identity, or lacking the capacity to act and express opinions as a collective may prove fatal for a collaborative network (ibid.). Thus, in networked collaboration, it is advisable to use communication technology solutions in a way that encourages all network members to communicate actively. Technology-mediated communication in a network is ideally a set of dialogical forms of interaction between network members and a means of coorientation toward common objectives. The importance of consensus-based decisions and participatory and equitable decision-making is emphasized in networked collaboration (Zhong et al. 2017). In interorganizational networks, members have different skills, varying backgrounds with respect to the previous use of communication technology, and typically, different expectations regarding technology-mediated communication. This diversity of members should be taken into account.

\section{Maintaining Different Kinds of Interpersonal Relationships at Work}

A fruitful way to foster online collaboration is the maintenance of interpersonal relationships with other collaborators. Individuals benefit from membership in a collaborative team or network only if they are able to build trusting interpersonal relationships with others and, at the same time, notice the web of interpersonal relationships they have with the other collaborators (Gupta, Ho, Pollack, \& Lai 2016).

In many cases, technology-mediated communication has increased the number of interpersonal relationships at work, because networked collaboration has become a common way of organizing work. Some of these interpersonal relationships become more important than others. In online collaboration, shared tasks and projects as well as shared work-related issues are important for building and maintaining close interpersonal relationships (Sias, Gallagher, Kopaneva, \& Pedersen 2012). These close relationships are more important for completing one's work, achieving work goals, and giving and receiving social support than others. When resources are limited, it may be useful to determine which of the interpersonal relationships are most important for one's work and to devote more effort to them. Putting effort into certain interpersonal relationships at work means maintaining those relationships, that is, either keeping them alive or developing them toward a desired state with active communication. Various applications can support the management of one's coworker 
relationships. For example, by means of instant messaging, the members of an interpersonal relationship can be reached quickly, and it is easy to ask questions and get feedback on demand (Ou \& Davison 2016).

However, interpersonal relationships at work are not without their complexities many of which are accentuated by communication technology. Especially in the case of socalled multiplex workplace friendships, in addition to their beneficial effects, they may have negative sides (Methot, Lepine, Podsakoff, \& Christian 2016). For example, in contemporary workplaces, technology such as social media may contribute to these complexities by making the inconsistencies between employees' personal and professional identities more transparent or by publicly calling attention to a close relationship between colleagues. This, in turn, may lead to the perception of unwanted cliques or feelings of favoritism (Pillemer \& Rothbard 2018). Put simply, the defining features of friendships may end up being in tension with the fundamental elements of organizational working life (ibid.). This should not be read as a discouragement of close interpersonal relationships at work. Rather, it is yet another affordance of communication technology that one should be aware of in order to make informed decisions and understand the way people choose to use or not to use technology at work.

\section{Practical Implications}

The first step in improving the way communication technology is used at work is to become aware of existing practices. What kind of communication processes and structures already exist or have existed before? What kind of communication technology is used, including the "shadow ICT," which is based on people's personal preferences and the tools they bring with them from outside the context of work? How is this technology used? What kind of face-toface communication exists, and how does it relate to technology-mediated communication? Who communicates with whom, how often, and how, using the communication technology at hand? Are certain employees passive, and are the reasons for their withdrawal related to technology or practices of communication? Do the more passive collaborators have access to the right tools? How do the members perceive the existing practices of technology-mediated communication? That is, which ones seem to be serving the purpose of work, which ones are seen as irritations, and which ones may have been perceived as useful at the beginning of the collaboration but are no longer seen the same way?

Asking these and similar questions can raise awareness of the status quo, and once that step is taken, it is then possible to attempt to change existing practices or create new 
ones. Because technology-mediated communication practices develop over time, changing them does not happen overnight, even when trying to replace clearly useless or inappropriate practices. Rather, structures will "resist" change, especially in cases in which the reason for the change is not clear to the participants. Collectively analyzing existing practices and needs in the workplace makes it possible to establish better objectives for the change at the outset.

First, facilitating something as complex as the communication reality of a workplace requires an analysis of the current situation. This can be done by mapping the available technology and their affordances and by recognizing the communication practices (structures) that have been established over time and that enable and limit certain types of communication behavior. For example, the way communication technology is used outside work may frame the way it is perceived and used at work. If the employees of an organization are used to sharing news or other content on social media in their private life, their habitual patterns of sharing are certain to influence the way they evaluate and use social media in the work setting. In order to uncover existing patterns of communication as well as the values and expectations connected to them, workplace communication should be analyzed on a fundamental level. How are new ideas created and problems solved, and how is knowledge shared? How do workplace members use the available communication infrastructure to provide feedback or social support? Only an understanding of the way technology-mediated communication processes take place, and of the path that led to the current situation, can point toward a concrete plan of action.

Second, communication is central to working together. Thus, it should be viewed as a core function that requires sufficient resources - especially time and prioritizing. Moreover, communication technology is not a neutral tool that can simply be tacked on to the workplace without a potentially major impact on the way the members perceive themselves, relate to one another, and do their work. This constitutive power of communication (and communication technology) highlights the importance of small, everyday actions in building both the larger social structure and the interpersonal relationships that are at its core.

Third, networks are realized in communication, and effective communication requires effort. An interorganizational professional network will remain an imagined structure until it is put into action through communication by the members. Participating actively in communication may require extra effort in the context of technology-mediated communication. For example, the contribution of a network member is not necessarily visible to others. The active sharing of activities helps other network members appreciate the work that has been done. This sharing also communicates a commitment to the workplace and to 
the goals of the collaboration. On the other hand, some contemporary communication tools are designed to support this process by leaving automatic trails or highlighting the contribution of each participant without extra effort on their part.

\section{What to Consider in the Workplace}

- When possible, one should choose communication technology that is easy to use or already familiar to the users.

- It is worthwhile carefully analyzing the technology-related communication practices of the team or network, such as how feedback is provided or how tasks are being negotiated.

- Collaborators should be encouraged to share their expectations and previous experiences of collaborating via technology-mediated communication.

- Awareness of the affordances of communication technology and the way it is being used outside the context of work facilitates the selection of the right solution for the task at hand.

- The importance of active communication for the collaboration should be verbalized.

- Leaders and managers should be aware of the importance of active and supportive communication.

- The affordances of the communication technology at hand should be utilized in making work and work processes visible to all members of the workplace.

- The benefits of building and maintaining interpersonal relationships should be recognized even when work processes can potentially operate without them (i.e., when such process are enabled by swift trust).

- One should devote sufficient time and resources to bring the changes to completion, when introducing a new communication technology to the workplace,

\section{References}

Avolio, B. J. \& Kahai, S. S. 2003. Adding the "e" to e-leadership: How it may impact your leadership. Organizational Dynamics 31(4), 325-338.

Baehr, C. \& Alex-Brown, K. 2010. Assessing the value of corporate blogs: A social capital perspective. IEEE Transactions on Professional Communication 53(4), 358-369.

Blöbaum, B. 2016. Key factors in the process of trust: On the analysis of trust under digital conditions. In B. Blöbaum (Ed.) Trust and communication in a digitized world: Models and concepts of trust research. Cham: Springer, 3-25.

Borgatti, S. P. \& Halgin, D. S. 2011. On network theory. Organization Science 22(5), 11681181 .

Boyd, D. M. \& Ellison, N. B. 2008. Social network sites: Definition, history, and scholarship. Journal of Computer-Mediated Communication 13, 210-230.

Chang, S. E., Liu, A. Y. \& Lin, S. 2015. Exploring privacy and trust for employee monitoring. Industrial Management \& Data Systems 115, 88-106.

Cheng, X., Yin, G., Azadegan, A. \& Kolfschoten, G. 2016. Trust evolvement in hybrid team collaboration: A longitudinal case study. Group Decision and Negotiation 25(2), 267-288. 
Choi, O.-K. \& Cho, E. 2019. The mechanism of trust affecting collaboration in virtual teams and the moderating roles of the culture of autonomy and task complexity. Computers in Human Behavior 91, 305-315.

Chory, R. M., Vela, L. E. \& Avtgis, T. A. 2016. Organizational surveillance of computermediated workplace communication: Employee privacy concerns and responses. Employee Responsibilities and Rights Journal 28, 23-43.

Choudrie, J. \& Zamani, E. D. 2016. Understanding individual user resistance and workarounds of enterprise social networks: The case of Service Ltd. Journal of Information Technology 31, 130-151.

Culnan, M. J. \& Markus, M. L. 1987. Information technologies. In F. M. Jablin, L. L. Putnam, K. H. Roberts \& L. W. Porter (Eds.) Handbook of organizational communication: An interdisciplinary perspective. Newbury Park, CA: Sage, 420-443.

Daft, R. L. \& Lengel, R. H. 1984. Information richness: A new approach to managerial behavior and organizational design. In L. L. Cummings \& B. Staw (Eds.) Research in organizational behaviour. Vol. 6. Greenwich, CT: JAI Press, 191-233.

Daft, R. L. \& Lengel, R. H. 1986. Organizational information requirements, media richness and structural design. Management Science 32, 554-571.

Dasgupta, P. 2011. Literature review: e-Leadership. Emerging Leadership Journeys 4(1), 136.

de Vries, J. R., van Bommel, S. \& Peters, K. 2018. Trust at a distance: Trust in online communication in environmental and global health research projects. Sustainability 10(11), 4005. doi.org/10.3390/su10114005.

Evans, S. K., Pearce, K. E., Vitak, J. \& Treem, J. W. 2017. Explicating affordances: A conceptual framework for understanding affordances in communication research. Journal of Computer-Mediated Communication 22, 35-52.

Gibson, J. J. 2015 [1986]. The ecological approach to visual perception. Classic ed. New York: Psychology Press.

Giddens, A. 1984. The constitution of society: Outline of the theory of structuration. Berkeley, CA: University of California Press.

Gilson, L. L., Maynard, M. T., Young, N. C. J., Vartiainen, M. \& Hakonen, M. 2015. Virtual teams research: 10 years, 10 themes, and 10 opportunities. Journal of Management 41(5), 1313-1337.

Gupta, N., Ho, V., Pollack, J. M. \& Lai, L. 2016. A multilevel perspective of interpersonal trust: Individual, dyadic, and cross-level predictors of performance. Journal of Organizational Behavior 37(8), 1271-1292.

Hämäläinen, R., Lanz, M. \& Koskinen, K. T. 2018. Collaborative systems and environments for future working life: Towards the integration of workers, systems and manufacturing environments. In Harteis, C. (Ed.) The impact of digitalization in the workplace: Professional and practice-based learning. Vol. 21. Cham: Springer, 25-38. 
Hart, R. K. \& McLeod, P. L. 2003. Rethinking team building in geographically dispersed teams: One message at a time. Organizational Dynamics 31(4), 352-361.

Hsu, J. S. C., Chang, J. Y. T., Klein, G. \& Jiang, J. J. 2009. Exploring the impact of team mental models on information utilization and project performance in system development. International Journal of Project Management 29, 1-12.

Jonassen, D. H. \& Kwon, H. I. 2001. Communication patterns in computer mediated versus face-to-face group problem solving. Education Technology Research and Development 49(1), $35-51$.

Karr-Wisniewski, P. \& Lu, Y. 2010. When more is too much: Operationalizing technology overload and exploring its impact on knowledge worker productivity. Computers in Human Behavior 26, 1061-1072.

Koschmann, M. A. 2016. The communicative accomplishment of collaboration failure. Journal of Communication 66, 409-432.

Leinonen, P. \& Bluemink, J. 2008. The distributed team members' explanations of knowledge they assume to be shared. Journal of Workplace Learning 20, 38-53.

Lewicki, R. J. \& Bunker, B. B. 1996. Developing and maintaining trust in work relationships. In R. M. Kramer \& T. R. Tyler (Eds.) Trust in organizations. Thousand Oaks, CA: Sage, 114-139.

Lin, Y. 2018. A comparison of selected Western and Chinese smart governance: The application of ICT in governmental management, participation and collaboration.

Telecommunications Policy 42(10), 800-809.

Methot, J. R., Lepine, J. A., Podsakoff, N. P., \& Christian, J. S. 2016. Are workplace friendships a mixed blessing? Exploring tradeoffs of multiplex relationships and their associations with job performance. Personnel Psychology 69(2), 311-355.

Meyerson, D., Weick, K. W., \& Kramer, R. M. 1996. Swift trust and temporary groups. In R. M. Kramer \& T. R. Tyler (Eds.) Trust in organizations: Frontiers of theory and research. Thousand Oaks, CA: Sage, 166-195.

Monge, P. R. \& Contractor, N. S. 2003. Theories of communication networks. Oxford: Oxford University Press.

Ou, C. X. J. \& Davison, R. M. 2016. Shaping guanxi networks at work through instant messaging. Journal of the Association for Information Science and Technology 67(5), 11531168 .

Pillemer, J. \& Rothbard, N. P. 2018. Friends without benefits: Understanding the dark sides of workplace friendship. Academy of Management Review 43(4), 1-26.

Planko, J., Chappin, M. M. H., Cramer, J. M., \& Hekkert, M. P. 2017. Managing strategic system-building networks in emerging business fields: A case study of the Dutch smart grid sector. Industrial Marketing Management 67, 37-51.

Poole, M. S. \& McPhee, R. D. 2005. Structuration theory. In S. May \& D. Mumby (Eds.) Engaging organizational communication theory and research. Norwood, NJ: Ablex, 171195. 
Scott, M. E. 2013. "Communicate through the roof": A case study analysis of the communicative rules and resources of an effective global virtual team. Communication Quarterly 61(3), 301-318.

Short, J., Williams, E., \& Christie, B. 1976. The social psychology of telecommunication. London: Wiley.

Sias, P. M. 2009. Organizing relationships: Traditional and emerging perspectives on workplace relationships. Thousand Oaks, CA: Sage.

Sias, P. M., Gallagher, E. B., Kopaneva, I., \& Pedersen, H. 2012. Maintaining workplace friendships: Perceived politeness and predictors of maintenance tactic choice.

Communication Research 39(2), 239-268.

Ter Hoeven, C. K., van Zoonen, W. \& Fonner, K. L. 2014. The practical paradox of technology: The influence of communication technology use on employee burnout and engagement. Communication Monographs 83(2), 239-263.

Walther, J. B. 1992. Interpersonal effects in computer-mediated interaction: A relational perspective. Communication Research 19, 52-90.

Walther, J. B. 1996. Computer-mediated communication: Impersonal, interpersonal, and hyperpersonal interaction. Communication Research 23(1), 3-43.

Wellman, B. \& Haythornthwaite, C. 2002. The internet in everyday life. Malden, MA: Blackwell.

Zhong, W., Su, C., Peng, J., \& Yang, Z. 2017. Trust in interorganizational relationships: A meta-analytic integration. Journal of Management 43(4), 1050-1075. 